\title{
A Novel Patient-Derived Cell Line of Adrenocortical Carcinoma Shows a Pathogenic Role of Germline MUTYH Mutation and High Tumour Mutational Burden
}

\author{
Laura-Sophie Landwehr \\ University Hospital Würzburg https://orcid.org/0000-0002-6315-4176 \\ Jochen Schreiner \\ University Hospital Würzburg \\ Silke Appenzeller \\ University of Würzburg \\ Stefan Kircher \\ University of Würzburg \\ Sabine Herterich \\ University Hospital Würzburg \\ Martin Fassnacht \\ University Hospital Würzburg \\ Matthias Kroiss \\ University Hospital Munich \\ Isabel Weigand ( $\boldsymbol{Q}$ isabel.weigand@med.uni-muenchen.de) \\ University Hospital Munich
}

\section{Research}

Keywords: base excision repair, oxidative stress, adrenal, steroid hormones

Posted Date: December 15th, 2020

DOI: https://doi.org/10.21203/rs.3.rs-125950/v1

License: (c) (i) This work is licensed under a Creative Commons Attribution 4.0 International License.

Read Full License 


\section{Abstract}

\section{Background}

The response of advanced adrenocortical carcinoma (ACC) to current chemotherapies is unsatisfactory and a limited rate of response to immunotherapy was observed in clinical trials. High tumour mutational burden (TMB) and the presence of a specific DNA signature are characteristic features of tumours with mutations in the gene MUTYHencoding the mutY DNA glycosylase. Both have been shown to potentially predict the response to immunotherapy. High TMB in an ACC cell line model has not been reported yet.

Methods

The JIL-2266 cell line was established from a primary ACC tumour, comprehensively characterised and oxidative damage, caused by a dysfunctional mutY DNA glycosylase, confirmed.

Results

Here, we characterise the novel patient-derived ACC cell line JIL-2266, which is deficient in MUTYHdependent DNA repair. JIL-2266 cells have a consistent STR marker profile that confirmed congruousness with primary ACC tumour. Cells proliferate with a doubling time of $41 \pm 13$ hours. Immunohistochemistry revealed positivity for steroidogenic factor-1. Mass spectrometry did not demonstrate significant steroid hormone synthesis. JIL-2266 have hemizygous mutations in the tumour suppressor gene TP53 (c.859G>T:p.E287X) and MUTYH(c.316C>T:p.R106W). Exome sequencing showed 683 single nucleotide variants and 4 insertions/deletions. We found increased oxidative DNA damage in the cell line and the corresponding primary tumour caused by impaired mutY DNA glycosylase function and accumulation of 8-oxoguanine.

Conclusion

This model will be valuable as a pre-clinical ACC cell model with high TMB and a tool to study oxidative DNA damage in the adrenal gland.

\section{Background}

Adrenocortical carcinoma (ACC) is a rare endocrine cancer affecting approximately 0.5 to 2 per million people annually [1]. About $60 \%$ of patients present symptoms of adrenal steroid excess, such as Cushing syndrome or virilisation [2]. Surgery is the only curative approach but many patients with ACC experience a relapse, even after complete surgical resection [3, 4]. Mitotane is the only approved drug in metastatic disease [5] and used both in a palliative and adjuvant setting [6, 7]. Objective response rate of advanced ACC is however low with only $20 \%$ [8] and severe adverse effects are common [2,9]. Combination of etoposide, doxorubicin and cisplatin (EDP) is the most effective cytotoxic chemotherapy, but median overall survival is still poor with only $12-15$ months [10]. 


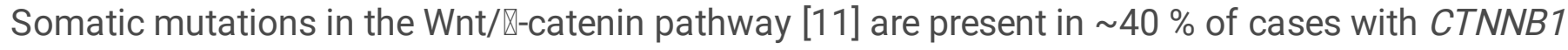
mutations present in $25 \%$ [12] and ZNRF3 mutations in $21 \%$ [13]. Inactivating mutations in the tumour suppressor TP53 occur in at least another $20 \%$ of sporadic ACC [11]. Increased expression of IGF2 (Insulin like growth factor 2) that is found in 90\% of ACC [14-16] provided the rationale for a phase III clinical trial with the selective small molecule IGF-1R inhibitor linsitinib but the results were disappointing [17]. Only few patients derive clinical benefit from multi-tyrosine kinase inhibitors that have been clinically tested [18].

Genetic predisposition to ACC includes Li-Fraumeni syndrome (LFS) caused by mutations in the tumour suppressor TP53 in 3-7 \% of ACC [19, 20]. Mutations in the mismatch repair (MMR) genes MSH2, MSH6, MLH1, PMS2 cause Lynch syndrome (LS) and have been found in at least $3 \%$ of ACC $[1,21]$. Impaired MMR protein function leads to high tumour mutational burden (TMB) and - consecutively - the presence of a high number of tumour specific neoantigens that may trigger an anti-tumoural immune response [22, 23].

While the overall response rate of ACC to immunotherapy in clinical trials was heterogeneous [24-26], 2/9 of ACC patients responding to the programmed cell death 1 (PD-1) inhibitor pembrolizumab in a clinical phase II trial had LS [27]. In a patient-derived mouse xenograft of a LS-associated ACC, experimental immune checkpoint inhibition led to increased antitumoural immune cell infiltration and consecutive treatment response [28].

Similar to LS-associated DNA repair deficiencies, inactivating mutations in the MUTYH gene involved in oxidative DNA damage repair confer a heritable predisposition to colorectal carcinoma termed MUTYHassociated polyposis. MUTYH-deficient tumours exhibit a high TMB and are responsive to immune checkpoint inhibition [29]. Two genome-wide studies identified MUTYH germline mutations in four ACC with high TMB [30].

Yet, cell culture models to investigate factors of response and resistance to T cell-mediated anti-tumoural response in ACC [31] are scarce. Until recently, H295R [32] cells first described in 1990 were the only available cell line. The first paediatric ACC patient-derived xenograft (PDX) model (SJ-ACC3) was reported by Pinto et al. [33] and in 2016, Hantel and colleagues successfully developed the first adult ACC PDX and established a respective cell line, termed MUC-1 [34]. The publication in 2018 of two additional PDXderived ACC cell lines including one from a LS patient [35] increased the number of available human ACC cell lines to four, which now allows comparative studies that better reflect the genetic heterogeneity of ACC $[16,36-38]$.

Here, we present a newly established ACC cell line with high mutational burden, which was generated directly from a patient-derived tumour. Since the development of the H295R cell line 30 years ago, this is the first ACC cell line that was transferred directly to cell culture.

\section{Materials And Methods}




\section{Patients}

All patients included were participants of the ENSAT (European Network for the Study of Adrenal Tumours) registry and biobank. The study was approved by the Ethics Committee of the University of Würzburg (\# 88/11) and all patients provided written informed consent for the use of tissue, cells, clinical data and genetic characterisation.

\section{Establishment of the ACC tumour cell line}

At the time of surgery, $1.3 \mathrm{mg}$ of the primary tumour were used for cell culture after removal of the surrounding fat tissue. The tumour piece was minced and a single cell suspension was obtained using the gentleMACS Dissociator and Tumour Dissociation Kit (both Miltenyi Biotec), following the manufacturer's instructions. Culture medium was supplemented with $5 \mu \mathrm{mol} / \mathrm{l}$ Rho-associated protein kinase (ROCK) inhibitor Y-27632 (Sigma-Aldrich), $10 \mu \mathrm{l} / \mathrm{ml}$ penicillin G/streptomycin (P/S, Sigma-Aldrich) and $250 \mu \mathrm{g} / \mathrm{ml}$ amphotericin B (Sigma-Aldrich) in adaption of a published protocol [39].

Cells were grown in 3:1 (v/v) Dulbecco's modified Eagle's medium - DMEM-high glucose and F12

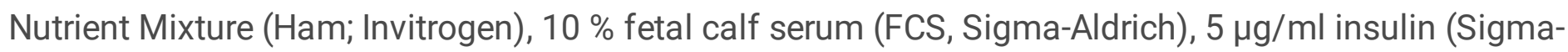
Aldrich), $0.4 \mu \mathrm{g} / \mathrm{ml}$ hydrocortisone (Sigma-Aldrich), $8.4 \mathrm{ng} / \mathrm{ml}$ cholera toxin (Sigma-Aldrich), $24 \mu \mathrm{g} / \mathrm{ml}$ adenine (Sigma-Aldrich) and $10 \mathrm{ng} / \mathrm{ml}$ epidermal growth factor (EGF, Invitrogen). H295R cells obtained from ATCC served as control and were cultured in DMEM:F12 medium supplemented with 1x insulintransferrin-selenium (ITS) and Nu-serum (2.5\%). Mycoplasma contamination was excluded at regular intervals by using the VenorßGeM Classic Mycoplasma Detection Kit (Minerva Biolabs).

\section{Cell experiments}

$2 \times 10^{7} \mathrm{JIL}-2266$ (passage (p) 25) and H295R cells ( $p$ 23) were harvested and washed twice with Dulbecco's phosphate buffered saline (DPBS, Sigma-Aldrich) at $1000 \mathrm{rpm}$ for 5 min at room temperature (RT). For induction of oxidative damage, $\mathrm{H} 295 \mathrm{R}$ cells were treated with $100 \mu \mathrm{M}$ hydrogen peroxide $\left(\mathrm{H}_{2} \mathrm{O}_{2}\right)$ for $20 \mathrm{~min}$ at $4^{\circ} \mathrm{C}$ and subsequently washed twice with DPBS (1000 rpm, $\left.5 \mathrm{~min}, \mathrm{RT}\right)$. After the last washing step, cell pellets were resuspended in $2 \mathrm{ml}$ paraformaldehyde (4\%) and kept in gentle movement at $4^{\circ} \mathrm{C}$ overnight. Suspensions were pelleted at maximal speed (15.000 rpm) using a microcentrifuge for 5 min. Pellets were incubated in $2 \mathrm{ml} 70 \%$ ethanol (EtOH) for $20 \mathrm{~min}$ and centrifuged at $1000 \mathrm{rpm}$ for 5 min. This was repeated with 85 \%, 96 \% EtOH and $100 \%$ isopropanol. After removal of the supernatant, 1 $\mathrm{ml}$ paraffin was added to cell pellets and the sample placed into a paraffin tank for $1 \mathrm{~h}$ at $60^{\circ} \mathrm{C}$.

Subsequently, embedded pellets were stored until slides were prepared.

For mitotane treatment, $3 \times 10^{4} \mathrm{JIL}-2266$ cells were seeded in black 96 -well plates with clear bottom. After 24 hours, cells were treated for another $24 \mathrm{~h}$ with mitotane (AlsaChim) dissolved in EtOH and viability was determined with CellTiter Glo Assay (Promega) as described before [36]. 
Formalin-fixed, paraffin-embedded (FFPE) slides of tumour tissue and cell pellets were deparaffinised twice in xylol for $25 \mathrm{~min}$ and subsequently rehydrated. Antigen retrieval was performed in $10 \mathrm{mM}$ citric acid monohydrate buffer $(\mathrm{pH} \mathrm{6.0)}$ ) for 13 min under pressure and endogenous peroxidase blocked with 3 $\% \mathrm{H}_{2} \mathrm{O}_{2}$. Unspecific binding sites were blocked with $20 \%$ human $A B$ serum for $1 \mathrm{~h}$ at RT. Primary antibodies against SF-1 (R\&D Systems, N1665, 1:200), Ki-67 (Dako, MIB-1, 1:800), Inhibin a (Serotec, R1, 1:20), PD-L1 (Cell Marque, 28-8, 1:100) and TP53 (Dako, D0-7, 1:200) were incubated for $1 \mathrm{~h}$ at RT. Signal amplification was achieved by the Advance HRP Link Kit for $40 \mathrm{~min}$ and slides developed with the DAB+ Liquid Kit (Dako) for 10 min. Nuclei were counterstained using Mayer's haematoxylin for 10 min and blued for $5 \mathrm{~min}$ in running tap water.

\section{Immunofluorescence}

FFPE slides were deparaffinised three times in xylol for 5 min and subsequently rehydrated. Slides were incubated with proteinase $\mathrm{K}$ for $30 \mathrm{~min}$ at RT and afterwards with $100 \mu \mathrm{g} / \mathrm{ml}$ RNAse A for $1 \mathrm{~h}$ at $37^{\circ} \mathrm{C}$. DNA was denatured in $2 \mathrm{~N} \mathrm{HCl}$ for 5 min and neutralized with $1 \mathrm{M}$ Tris-base. Unspecific binding sites were blocked in $10 \%$ goat serum for $1 \mathrm{~h}$. Incubation with primary antibody (8-oxoG, Trevigen, \#15A3), occurred in a dilution of $1: 250$ in DPBS with $0.1 \% \mathrm{BSA}(\mathrm{w} / \mathrm{v})$ at $4{ }^{\circ} \mathrm{C}$ overnight. The primary antibody was omitted in negative controls. Secondary antibody (goat-anti-mouse Alexa Fluor488, ThermoFisher) was incubated in the dark for $1 \mathrm{~h}$ at RT at a dilution of 1:200 in PBS with $0.1 \%$ BSA (w/v). Nuclei were stained with DAPI (1:1000) for 3 min in the dark, slides washed with DPBS and mounted with ProLong Gold Antifade (ThermoFisher). Analyses of immune cell infiltrates were performed as described previously [31].

\section{Microscopy}

Microphotographs were taken with the Leica Aperio slide scanner (20 x objective) and processed with Aperio Image Analysis software (chromogenic immunohistochemistry) or the Zeiss Axioscope.A1 microscope (40 x objective) equipped with a Zeiss Axiocam 503 mono (immunofluorescence).

\section{Extraction of DNA and RNA, qPCR}

Pathological anatomical assessment confirmed high tissue quality and the presence of $90 \%$ vital tumour cells by haematoxylin-eosin staining. Genomic DNA was isolated from fresh frozen ACC tumour, cell line $(p 6,8,13,29)$ and patient-matched leukocytes by using the Maxwell RSC Blood DNA Kit (Promega). DNA concentration was determined by Nanodrop spectrophotometer (Thermo Fisher).

RNA from fresh frozen tissue and cell lines was isolated for gene expression analyses with the Maxwell RSC Simply RNA Kit (Promega). RNA concentration was determined by Nanodrop Spectrophotometer (Thermo Fisher) and 1000 ng RNA were reverse transcribed with the QuantiTect Reverse Transcription Kit (Qiagen). Quantitative reverse transcriptase PCR (RT-qPCR) was performed using TaqMan gene expression probes (Thermo Fisher Scientific) for MC2R (Hs00300820), PINK1 (Hs00260868), BUB1B (Hs01084828), CTNNB1 (Hs00355049), SREBP1 (Hs01088691), SREBP2 (Hs01081784), CYP11B1 (Hs01596404), CYP11B2 (Hs01597732), STAR(Hs00264912). Endogenously expressed ACTB 
(Hs99999903) was used as housekeeping gene for normalization. For each RT-qPCR reaction, $5 \mathrm{ng}$ cDNA were used and each sample was analysed in technical duplicates. All transcripts were amplified using TaqMan Gene Expression Master Mix (Thermo Fisher) using the CFX96 real-time thermocycler (Bio-rad) and the Bio-rad CFX Manager 2.0 software. Cycling conditions were $95^{\circ} \mathrm{C}$ for $3 \mathrm{~min}$, followed by 39 cycles of $95^{\circ} \mathrm{C}$ for $30 \mathrm{sec}, 60^{\circ} \mathrm{C}$ for $30 \mathrm{sec}$ and $72^{\circ} \mathrm{C}$ for $30 \mathrm{sec}$. Fold change was calculated using the $\triangle \mathrm{CT}$ method, normalized to housekeeping gene $\beta$-actin.

\section{Short tandem repeat (STR) profiling}

DNA from JIL-2266 cells and corresponding leukocytes from donor patient was extracted using the Maxwell RSC Blood DNA Kit (Promega). Typing was performed using the STR-loci VWA, THO1, TPOX, CSF1PO, D16S539, D13S317, D7S820, D5S818 and the amelogenin sex-determining marker (AMELlocus) to show patient originality, analyse congruousness and to rule out cross-contamination in the course of cultivation after $p 5,8,13$, and 29. Loci were amplified and electrophoretic analysis was carried out with the GeXP-instrument (AB Sciex). Data were analysed using the GeXP fragment analysis software.

\section{Proliferation assay}

$1 \times 10^{5} \mathrm{JIL}-2266(\mathrm{p} 30,32,33)$ and NCl-H295R per well were seeded into a 12-well plate. After $24 \mathrm{~h}, 48 \mathrm{~h}$ and $72 \mathrm{~h}$, cells were harvested with trypsin and numbers were quantified in duplicates by using the Countess ${ }^{\circledR}$ Automated Cell Counter (ThermoFisher). Doubling time was determined using the exponential growth function in GraphPad Prism 8 software [40].

\section{LC-MS/MS measurement of steroid hormones}

JIL-2266 cells $\left(2 \times 10^{6}\right)$ were plated in 6-well plates in $2 \mathrm{ml} \mathrm{DMEM/F12} \mathrm{medium} \mathrm{supplemented} \mathrm{with} 5 \%$ FCS and P/S for $48 \mathrm{~h}$ and stimulated with $10 \mu \mathrm{M}$ forskolin (Santa Cruz Biotechnology) or $10 \mathrm{ng} / \mathrm{ml}$ EGF (Invitrogen), $5 \mu \mathrm{g} / \mathrm{ml}$ insulin (Sigma-Aldrich) and $24 \mu \mathrm{g} / \mathrm{ml}$ adenine (Sigma-Aldrich) for $48 \mathrm{~h}$. Supernatants were collected and steroids were quantified with the MassChrom steroids kit (Chromsystems) on a Qtrap 6500+ (Sciex) mass spectrometer coupled to a 1290 Infinity HPLC System (Agilent). Signal analysis was performed with Analyst Software (1.6.3, Sciex) as described elsewhere [41].

\section{Library preparation}

SureSelectXT Human All Exon V6 Kit (Agilent) was used for library preparation. Paired end sequencing with a read length of 100 base pairs (bps) was performed on a NovaSeq 6000 (Illumina). For the library preparation of the tumour and matched control sample, the xGen Exome Research Panel v2 (Integrated DNA Technologies) was used and paired end sequencing with a read length of 150 bps was performed on a NextSeq 500 (Illumina).

\section{Bioinformatics}


After an initial quality assessment using FastQC, v0.11.5 (Andrews S., 2010. available online at: http://www.bioinformatics.babraham.ac.uk/projects/fastqc), adapters and low-quality reads were trimmed with TrimGalore, v0.4.0 (Krueger, F., 2012: available online at: http://www.bioinformatics.babraham.ac.uk/projects/trim_galore/) powered by Cutadapt, v1.8 [42]. The trimmed reads were mapped to the UCSC human genome (hg19) with BWA mem, v 0.7.17 [43], sorted and indexed using Picard, v1.125 (available online at: http://broadinstitute.github.io/picard/) and SAMtools, v1.3 [44] respectively. Duplicates were marked with Picard. For coverage calculations and base quality score recalibration, GATK3, v3.5 and GATK4, v4.0.11.0 [45] were used, respectively.

For germline variant calling, we used GATK3 and GATK4. MuTect2 integrated in the GATK4 package was used for somatic variant calling. All variants were annotated with ANNOVAR, v2019-10-24 [46] and considered if they were below a frequency of $2 \%$ in the databases $1000 \mathrm{~g} 2015$ aug_all, ExAC_nontcga_ALL, gnomAD_exome_ALL and gnomAD_genome_ALL, if the position is covered by at least 20 reads and the alternative allele is covered by at least 8 reads and comprised at least $10 \%$ of the total reads. The filtered MuTect2 results were used for TMB calculations. Mutational signatures were identified using MutaGene [47]. For this analysis, synonymous variants were also included.

\section{Results}

\section{Case presentation}

The donor of the tissue was a female 50 years old patient who presented with severe Cushing's syndrome including hypertension, muscle weakness, hypokalaemia and lymphopenia. Computer tomography scan indicated a left adrenal mass with a maximum of $9 \mathrm{~cm}$ diameter and pulmonary metastases. Endocrine work-up according to current guidelines [4] revealed androgen and cortisol excess (including pathological dexamethasone suppression test). Adrenolytic therapy with mitotane and metyrapone was initiated to ameliorate Cushing's syndrome, followed by left adrenalectomy two weeks later. Routine histological examination confirmed the diagnosis of an advanced high-grade ACC (35 mitoses / 10 high power fields (HPF)), Ki67 proliferation index of $60 \%$ up to $90 \%$ and a Weiss score of 9 . By immunohistochemistry, the tumour was positive for steroidogenic factor-1 (SF-1) and partially for inhibin a. In line with our previous study of immune cells in ACC [31], the donor tumour was infiltrated by $\mathrm{CD}^{+}{ }^{-}, \mathrm{CD}^{+}$- and $\mathrm{CD} 8^{+} \mathrm{T}$ lymphocytes to a moderate extent $(7.8,3.3$ and $5.2 \mathrm{~T}$ cells per HPF, respectively;

Figure $1 \mathrm{~A}$ ). Programmed cell death-ligand 1 was expressed in less than $1 \%$ of tumour cells and DNA MMR protein expression was normal. After surgery, the patient received chemotherapy with EDP in addition to mitotane. After two cycles, the patient experienced rapid progression of pulmonary metastases, new liver metastases and died shortly thereafter.

The family history was remarkable with a cerebellar tumour not otherwise specified in the mother and breast cancer in the sister and grandmother. LFS was excluded by routine germline sequencing of TP53. 
Tumour material was obtained from surgical resection and subsequently enzymatically processed. By using chemically modified polystyrene Primaria culture flasks with a 1:1 ratio of nitrogen and oxygen and without $\mathrm{CO}_{2}$ supply, the generated cell suspension was initially cultured in the presence of ROCK inhibitor supporting immortalization of human tumours [39]. Subsequently, cells initially grew in primary culture preferably in colonies. By means of weakly renewal of media up to one half, cells started to proliferate and were passaged first after 180 days. While the time interval for passaging decreased to 90 days, fibroblast removal was performed after further 270 days at $p 4$. By consistent appearance, the new cell line proliferated until confluence for further 50 days. At that point, the cells were termed JIL-2266 and routinely passaged with further declining intervals (from $168 \mathrm{~h}$ to $41 \mathrm{~h}$ ) and characterised.

To confirm match of the cell line and the corresponding human blood sample, STR profiling was performed. JIL-2266 cells only exhibited alleles expressed in the corresponding human blood DNA, confirming the authenticity and correspondence between cell line and respective human tissue. For three loci - THO1 (chromosomal localization: 11p15.5; intron 1 tyrosine-hydroxylase gene), D16S539 (chromosomal localization: 16q24.1) and TPOX (chromosomal localization: 2p25.3; intron 10 thyroidperoxidase gene) - the JIL-2266 cell line demonstrated loss of heterozygosity (LOH) (Table 1). Comparison with large cell line STR profile databases (DSMZ online STR analysis https://www.dsmz.de/services/human-and-animal-cell-lines/online-str-analysis) provided the proof of a unique genomic identity and excluded cross-contamination.

Immunohistochemistry reveals similarity between primary tumour and JIL-2266 cells

For confirmation of the adrenocortical origin of JIL-2266 cells and comparison with the standard ACC cell line H295R, immunohistochemistry of the primary tumour and cell pellets was performed. SF-1 was moderately expressed in the corresponding primary tumour and in JIL-2266 cells, while H295R cells showed a very strong SF-1 expression (Figure 1 B). The primary tumour showed only partial expression of inhibin a with very localized positive areas, while inhibin a expression was completely absent in the corresponding cell line JIL-2266. H295R cells showed strong inhibin a expression (Figure 1 C). Ki-67 and TP53 expression were high in the primary tumour, JIL-2266 and H295R cells (Figure 1 D and E). Analysis of cell pellets revealed a larger size of JIL-2266 compared to H295R cells (Figure 1). JIL-2266 cells grow adherent to the plastic bottom of the culture flask and morphological investigation of $p 8,14$ and 30 confirmed morphological stability during multiple passaging steps and over time (Figure S1).

mRNA expression of adrenal gland markers

Expression of adrenocortical markers transcripts by qPCR showed similar expression of PINK1, BUB1B and $C T N N B 1$ in the matching primary tumour and JIL-2266 cells with insignificant differences between passages (Figure 2). BUB1B was overexpressed in all ACC samples compared to normal adrenal gland (nAG). Expression of adrenal cortex markers was variable and lower in all ACC samples compared to nAG. MC2R expression was undetectable in JIL-2266 cells and highest expression of steroidogenic markers were observed for SREBP1 and SREBP2 (Figure 2). 
The proliferation rate of the H295R was $36 \pm 15$ hours (Figure 3 A) and $41 \pm 13.6$ hours for the JIL-2266 ( $p$ 30 , Figure $3 \mathrm{~B}$ ). The $\mathrm{EC}_{50}$ value for $24 \mathrm{~h}$ mitotane treatment was significantly higher with $8.3 \times 10^{-5} \mathrm{M}$ (Figure 3 C) in JIL-2266 compared to H295R cells $\left(1.8 \times 10^{-5}\right)$ [48].

\section{Steroid hormone profiling}

LC-MS/MS analysis of steroid hormones in standard cell culture medium showed undetectable quantities of adrenal steroid hormones independent of the passage (Table S1). $48 \mathrm{~h}$ treatment with forskolin did not result in detectable steroidogenesis of JIL-2266 cells (Table S1). Yet, when JIL-2266 cells were cultured with adenine, insulin, EGF and cholera toxin, small amounts of the androgens and the precursors progesterone, 17-OH-progesterone, DHEA, androstenedione and testosterone were detectable, which decreased with higher passages (FigureS2 and Table S1). These in vitro data are consistent with the plasma steroid hormone profile in the donor who had increased androstenedione, testosterone and 17OH-progesterone.

\section{Whole exome sequencing}

Exome sequencing revealed the presence of a pathogenic germline mutation in the MUTYH gene (MUTYH: NM_012222.2:exon3:c.316C>T:p.R106W), encoding the mutY DNA glycosylase.

By comparing exome sequencing data from primary tumour and the JIL-2266 cell line with donor leukocytes DNA as reference, 556 somatic genetic variants - single nucleotide variants and small insertions/deletions (InDels) - were found in the primary tumour and 683 variants in JIL-2266 cells, with 512 shared alterations. The number of genetic variants increased from $556 \mathrm{SNVs} / \mathrm{InDels}$ per exome in the primary tumour to 683 in JIL-2266 cell line (Figure 4 A). TP53 was hemizygous for a stop gain mutation (TP53: NM_000546.5:exon8:c.859G>T:p.E287X) both in the patient's primary tumour and JIL-2266 cell line. Additionally, a LOH in the MUTYH gene (MUTYH: NM_012222.2:exon3:c.316C>T:p.R106W) in both primary tumour and cell line compared to patient blood DNA was found (Figure $4 \mathrm{~B}$ ). While both the primary tumour and JIL-2266 cell line held a wild type CTNNB1 allele, they showed a somatic nucleotide variants in the ZNRF3 gene (ZNRF3: NM_001206998.2:exon8:c.2569G>T:p.G857W). The complete list of somatic alterations and their characteristics is shown in supplementary Table S2. By applying gene signature analysis, we found prevalent cytosine (C) > adenine (A) single base substitutions corresponding to signature 18 in the Catalogue of Somatic Mutations in Cancer (COSMIC) database (https://cancer.sanger.ac.uk/cosmic/signatures_v2.tt) in line with MUTYH deficiency.

\section{Functional assessment of the pathogenic MutY DNA glycosylase}

One of the most frequent types of oxidative DNA damage is 8-oxoguanine (8-oxoG) formation. 8-oxoG mispairs with adenine during replication [49], which is counteracted by base excision repair (BER) in a complex that includes MutY. Mutations that compromise MutY function hence lead to the accumulation 
of 8-oxoG leading to an increase of G:C>T:A transversions. We performed immunocytochemistry of 8OXOG in FFPE tissues of the corresponding primary tumour and a MUTYHWT ACC and in parallel, in cell pellets of JIL-2266, $\mathrm{H} 295 \mathrm{R}$ and $\mathrm{H} 295 \mathrm{R}$ cells pre-treated with $\mathrm{H}_{2} \mathrm{O}_{2}$ to induce oxidative damage. $\mathrm{H} 295 \mathrm{R}$ cells without prior $\mathrm{H}_{2} \mathrm{O}_{2}$ treatment were negative for 8-oxoG (Figure $5 \mathrm{~A}$ ), while $\mathrm{H}_{2} \mathrm{O}_{2}$ treatment led to a marked accumulation of 8-oxoG in NCl-H295R cells (Figure 5 B). Untreated JIL-2266 cells (Figure 5 C) and fresh frozen tumour (Figure 5 D) stained strongly positive for 8-oxoG while ACC with MUTYHWT allele was completely 8-oxoG negative, in line with our expectation of a causative role of MUTYH mutation for high TMB with COSMIC signature 18 (Figure $5 \mathrm{E}$ ).

Taken together, this novel human ACC cell line exhibits high TMB caused by oxidative DNA damage that fails to be counteracted by BER due to pathogenic MUTYH mutation.

\section{Discussion}

ACC is a very rare and heterogeneous malignancy and the development of new and effective treatment options is significantly hampered by the lack of pre-clinical models that mirror the clinically heterogeneous picture of the disease. Here we describe a novel patient-derived ACC cell line, JIL-2266, which is to our knowledge the first cell line since 30 years that was established by direct transfer into cell culture. Interestingly, JIL-2266 harbour a high TMB due to a pathogenic MUTYH mutation.

SF-1 positivity is an essential marker of adrenal cortical origin [50]. Both JIL-2266 cells and its corresponding tumour show moderate SF-1 expression (Figure 1 B). JIL-2266 cells also express additional adrenal markers involved in steroidogenesis albeit at lower levels than H295R cells; however, both less in comparison to normal adrenal glands. This is in line with low expression of steroidogenic enzymes and absent steroid hormone secretion in the JIL-2266 cell line under basal conditions; only seemingly in contrast to the clinical presentation of the patient who had pre-operative pathological elevation of steroid blood concentration. Indeed, the very high tumour burden in the presence of rather low steroidogenic capacity of tumour cells may explain the discrepancy. In general, steroid hormone secretion is variable in the JIL-2266 cells and similarly dependent on cell culture supplements and passage as in H295R cells [41]. Lower steroid secretion was associated with higher passages (Figure S2). It is conceivable that the accumulation of mutations with increasing passage negatively affects the cells' steroidogenic capacity. ACC markers PINK1, BUB1B and CTNNB1 were lower in the JIL-2266 cell line compared to H295R cells. Yet, expression was similar to that in the primary tumour.

Within the last few years, three new ACC cell lines $[34,35]$ were developed in addition to the bona fide cell line H295R, which has been excessively studied since its establishment in the early 1990s [32]. All available cell lines have mutations in TP53 (MUC-1, CU-ACC2), CTNNB1 (CU-ACC1) or both (H295R) [33, $34,35]$. JIL-2266 cells are not an exception as they also harbour a probably hemizygous TP53 mutation (NM_000546.5:exon8:c.859G>T: p.E287X). 
Mutations in DNA repair mechanisms have been found in a small proportion of ACC and mostly affect DNA MMR genes. MUTYH encodes a MutY DNA glycosylase and is part of the BER involved in the recognition and resolution of 8-oxoG-adenine mismatches by excising the mis-paired adenine. Sporadic cases of ACC have been shown to harbour MUTYH mutations. Pilati et al. described two hyper-mutated ACC tumours dominated by $\mathrm{C}>\mathrm{A}$ transversions and germline MUTYH mutation (ACC33:

NM_001128425.1:c.1187G>A, p.Gly396Asp and ACC39: NM_001128425.1:c.721C>T, p.Arg241Trp) [13]. Additionally, by analysing the TCGA cohort consisting of 91 ACCs, once again two tumours with COSMIC signature 18 and rare pathogenic MUTYH mutations (A: NM_001128425.1:c.467G>A; p.Trp156* and B: NM_001128425.1:c.536A>G, p.Tyr179Cys) were observed [11, 30].

Yet, the MUTYH(NM_012222.2:exon3:c.316C>T: p.R106W) mutation identified in our ACC patient and the derived JIL-2266 cell line has not been described in ACC but was observed in colorectal cancer [51]. This mutation was heterozygous in the germline of the patient and became hemizygous in the tumour. The observed strong accumulation of 8-OxOG in the primary tumour and JIL-2266 cell line, to a comparable extent as observed in $\mathrm{H} 295 \mathrm{R}$ cells exposed to oxidative stress $\left(\mathrm{H}_{2} \mathrm{O}_{2}\right.$ treatment), suggests a strong impairment in MutY DNA glycosylase function due to the mutation identified. Impaired DNA repair is further indicated by the increase of TMB in the JIL-2266 cell line after excessive passaging and replications compared to the primary tumour as revealed by exome sequencing. Our cell line exhibited the distinctive COSMIC mutational signature 18 associated with oxidative DNA damage and characterised by an enrichment of $\mathrm{C}>\mathrm{A}$ transversions $[30,49]$ caused by MUTYH mutations. COSMIC signature 18 has been rarely described in ACC and all these tumours were found to harbour MUTYH mutations [30].

PD-1 checkpoint inhibition may be particularly valuable in patients with DNA repair defects; the PD-1 inhibitor pembrolizumab is FDA-approved for MMR deficient or microsatellite instability high (MSI-H) solid tumours regardless of its origin. ACC has been shown to be associated with germline mutations in DNA MMR genes and hence LS-associated tumour [21,52]. While the overall response to immunotherapy in ACC patients is heterogeneous [24, 27] and not certainly associated with PD-L1 expression status [27], results from clinical trials [27] and case reports of successful PD-1 inhibition in MMR deficient patients are encouraging [53]. Hence, our novel cell line, derived from a primary tumour with present tumourinfiltrating lymphocytes also shows a deficient DNA repair mechanism and high TMB, which combined present a unique model to study antitumoural response to immunotherapy in vitro. Accordingly, a MMR deficient, high TMB humanized CU-ACC2 PDX demonstrated a significant increased immune infiltration following PD-1 inhibition and tumoural response to treatment [28].

Consistent with failure of the patient's tumour to respond to mitotane treatment, JIL-2266 cells were unresponsive to mitotane in culture. The patient's rapid disease progression precluded a therapeutic attempt with immune checkpoint inhibitors that have been demonstrated to be effective in other MUTYHmutated tumours [29].

\section{Conclusion}


The newly developed JIL-2266 ACC cell line presents an additional and valuable tool reflecting the genetic heterogeneity of ACC. JIL-2266 will enable a better understanding of mutY DNA glycosylase function in ACC and allows to study further the mechanisms of resistance to mitotane. Moreover, this new ACC cell line exhibits high TMB and COSMIC signature 18 and will be valuable for the assessment of mechanisms underlying response and resistance to immunotherapy in ACC.

MUTYH should be included in the genetic counselling and testing strategy of ACC to identify patients who potentially respond to immunotherapy $[29,52,53,56]$.

\section{Abbreviations}




\begin{tabular}{|c|c|}
\hline${ }^{\circ} \mathrm{C}$ & degree Celsius \\
\hline 17-OH progesterone & 17a-hydroxyprogesterone \\
\hline 8-OXOG & 8-oxoguanine \\
\hline A & adenine \\
\hline ACC & adrenocortical carcinoma \\
\hline ACTB & beta-actin \\
\hline BER & base excision repair \\
\hline BPS & base pairs \\
\hline BSA & bovine serum albumin \\
\hline C & cytosine \\
\hline CD3 & cluster of differentiation 3 \\
\hline CD4 & cluster of differentiation 4 \\
\hline CD8 & cluster of differentiation 8 \\
\hline cDNA & complementary Deoxyribonucleic acid \\
\hline $\mathrm{CO}_{2}$ & carbon dioxide \\
\hline cosmic & catalogue of somatic mutations in cancer \\
\hline CTNNB1 & $\beta$-catenin 1 \\
\hline CYP11B1 & cytochrome P450 11B1 \\
\hline CYP11B2 & cytochrome P450 11B2 \\
\hline DAB & 3,3'-diaminobenzidine \\
\hline DAPI & 4',6-diamidino-2-phenylindole \\
\hline DHEA & dehydroepiandrosterone \\
\hline DMEM & Dulbecco's modified Eagle's medium \\
\hline DNA & deoxyribonucleic acid \\
\hline DPBS & Dulbecco's phosphate buffered saline \\
\hline $\mathrm{EC}_{50}$ & half maximal effective concentration \\
\hline EDP & etoposide, doxorubicin and cisplatin \\
\hline EGF & epidermal growth factor \\
\hline ENSAT & European Network for the Study of Adrenal Tumours \\
\hline
\end{tabular}




\begin{tabular}{|c|c|}
\hline $\mathrm{EtOH}$ & ethanol \\
\hline FCS & fetal calf serum \\
\hline FDA & food and drug administration \\
\hline FFPE & formalin-fixed-paraffin-embedded \\
\hline $\mathrm{h}$ & hour \\
\hline $\mathrm{H}_{2} \mathrm{O}_{2}$ & hydrogen peroxide \\
\hline $\mathrm{HCl}$ & hydrochloric acid \\
\hline HPF & high power fields \\
\hline HRP & horseradish peroxidase \\
\hline IGF2 & insulin like growth factor 2 \\
\hline IGF-R1 & insulin like growth factor receptor 1 \\
\hline InDels & Insertion/deletions \\
\hline ITS & insulin-transferrin-selenium \\
\hline LC-MS/MS & liquid chromatography-mass spectrometry - tandem mass spectrometry \\
\hline LFS & Li-Fraumeni syndrome \\
\hline $\mathrm{LOH}$ & loss of heterozygosity \\
\hline LS & Lynch syndrome \\
\hline MC2R & melanocortin receptor 2 \\
\hline $\min$ & minute \\
\hline MLH1 & mutL homolog 1 \\
\hline MMR & mismatch repair \\
\hline MSH2 & mutS homolog 2 \\
\hline MSH6 & muts homolog 6 \\
\hline MSI & microsatellite instability \\
\hline MSI-h & microsatellite instability high \\
\hline MUT & mutant \\
\hline MUTYH & mutY DNA glycosylase \\
\hline nAG & normal adrenal gland \\
\hline $\mathrm{p}$ & passage \\
\hline
\end{tabular}




\begin{tabular}{ll} 
P/S & penicillin G/streptomycin \\
\hline PD-1 & programmed cell death 1 \\
\hline PD-L1 & programmed cell death ligand 1 \\
\hline PDX & patient-derived xenograft \\
\hline PINK1 & PTEN-induced kinase 1 \\
\hline qPCR & quantitative polymerase chain reaction \\
\hline RNA & ribonucleic acid \\
\hline RNAse A & ribonuclease A \\
\hline ROCK & rho-associated protein kinase \\
\hline rPm & rounds per minute \\
\hline RT & room temperature \\
\hline RT-qPCR & real-time quantitative polymerase chain reaction \\
\hline SF-1 & steroidogenic factor-1 \\
\hline SNV & single nucleotide variant \\
\hline SREBP1 & sterol regulatory element-binding transcription factor 1 \\
\hline SREBP2 & sterol regulatory element-binding transcription factor 2 \\
\hline STAR & steroidogenic acute regulatory protein \\
\hline STR & short tandem repeat \\
\hline TMB & tumour mutational burden \\
\hline TP53 & zinc and ring finger 3 \\
\hline WT & \\
\hline ZNRF3 & \\
\hline
\end{tabular}

\section{Declarations}

\section{Ethics approval and consent to participate}

All patients included were participants of the ENSAT (European Network for the Study of Adrenal Tumours) registry and biobank. The study confirmed to the principles of the Declaration of Helsinki, the Good Clinical Practice Guidelines and was approved by the Ethics Committee of the University of Würzburg (\# 88/11). All patients provided written informed consent for the use of tissue, cells, clinical data and genetic characterisation. 


\section{Consent for publication}

This manuscript does not contain personal and/or medical information about identifiable living individual. All patients were anonymised and provided written informed consent.

\section{Availability of data and materials}

All data generated or analysed during relevant to the current study are included in the article, uploaded as supplementary information or are available from corresponding author on reasonable request.

\section{Competing Interests}

The authors declare no competing interest.

\section{Funding}

This research work was funded by the German Research Council project 237292849 (to MK and MF) and project 314061271- TRR 205 (project B16, B20 and S1, to M.F. and M.K.).

\section{Author's contributions}

IW and MK participated in the study design and supervision. MF and MK were responsible for funding acquisition. LSL, JS, SA, SH, SK and IW performed the experiments and are involved in data analyses. LSL, JS, MK and IW prepared and edited the final manuscript. All authors read and approved the final manuscript for publish.

\section{Acknowledgements}

The authors cordially thank patients and families for their commitment and compliance for attendance at regular follow-up ensuring collection of clinical data and for the confidence regarding use of tissue and genetic characterisation. Additionally, the authors thank Dr. Max Kurlbaum and Sabine Kendl for performing the LC-MS/MS measurements of steroid hormones and Dr. Holger Schneider for critically reading the manuscript.

\section{References}

1 Else T, Kim AC, Sabolch A, Raymond VM, Kandathil A, Caoili EM et al. Adrenocortical carcinoma. Endocr Rev 2014; 35: 282-326.

2 Fassnacht M, Allolio B. Clinical management of adrenocortical carcinoma. Best Pract Res Clin Endocrinol Metab 2009; 23: 273-289.

3 Grubbs EG, Callender GG, Xing Y, Perrier ND, Evans DB, Phan AT et al. Recurrence of adrenal cortical carcinoma following resection: surgery alone can achieve results equal to surgery plus mitotane. Ann Surg Oncol 2010; 17: 263-270. 
4 Fassnacht M, Dekkers OM, Else T, Baudin E, Berruti A, de Krijger R et al. European Society of Endocrinology Clinical Practice Guidelines on the management of adrenocortical carcinoma in adults, in collaboration with the European Network for the Study of Adrenal Tumours. Eur J Endocrinol 2018; 179: G1-G46.

5 Kerkhofs TM, Verhoeven RH, Van der Zwan JM, Dieleman J, Kerstens MN, Links TP et al. Adrenocortical carcinoma: a population-based study on incidence and survival in the Netherlands since 1993. Eur J Cancer 2013; 49: 2579-2586.

6 Terzolo M, Angeli A, Fassnacht M, Daffara F, Tauchmanova L, Conton PA et al. Adjuvant mitotane treatment for adrenocortical carcinoma. N Engl J Med 2007; 356: 2372-2380.

7 Berruti A, Grisanti S, Pulzer A, Claps M, Daffara F, Loli P et al. Long-Term Outcomes of Adjuvant Mitotane Therapy in Patients With Radically Resected Adrenocortical Carcinoma. J Clin Endocrinol Metab 2017; 102: 1358-1365.

8 Megerle F, Herrmann W, Schloetelburg W, Ronchi CL, Pulzer A, Quinkler M et al. Mitotane Monotherapy in Patients With Advanced Adrenocortical Carcinoma. J Clin Endocrinol Metab 2018; 103: 1686-1695.

9 Daffara F, De Francia S, Reimondo G, Zaggia B, Aroasio E, Porpiglia F et al. Prospective evaluation of mitotane toxicity in adrenocortical cancer patients treated adjuvantly. Endocr Relat Cancer 2008; 15: 1043-1053.

10 Fassnacht M, Terzolo M, Allolio B, Baudin E, Haak H, Berruti A et al. Combination chemotherapy in advanced adrenocortical carcinoma. N Engl J Med 2012; 366: 2189-2197.

11 Zheng S, Cherniack AD, Dewal N, Moffitt RA, Danilova L, Murray BA et al. Comprehensive Pan-Genomic Characterization of Adrenocortical Carcinoma. Cancer Cell 2016; 30: 363.

12 Tissier F, Cavard C, Groussin L, Perlemoine K, Fumey G, Hagnere AM et al. Mutations of beta-catenin in adrenocortical tumours: activation of the Wnt signaling pathway is a frequent event in both benign and malignant adrenocortical tumours. Cancer Res 2005; 65: 7622-7627.

13 Assie G, Letouze E, Fassnacht M, Jouinot A, Luscap W, Barreau 0 et al. Integrated genomic characterization of adrenocortical carcinoma. Nat Genet 2014; 46: 607-612.

14 Giordano TJ, Thomas DG, Kuick R, Lizyness M, Misek DE, Smith AL et al. Distinct transcriptional profiles of adrenocortical tumours uncovered by DNA microarray analysis. Am J Pathol 2003; 162: 521531.

15 Giordano TJ, Kuick R, Else T, Gauger PG, Vinco M, Bauersfeld J et al. Molecular classification and prognostication of adrenocortical tumours by transcriptome profiling. Clin Cancer Res 2009; 15: 668-676. 
16 Liang R, Weigand I, Lippert J, Kircher S, Altieri B, Steinhauer S et al. Targeted Gene Expression Profile Reveals CDK4 as Therapeutic Target for Selected Patients With Adrenocortical Carcinoma. Front Endocrinol (Lausanne) 2020; 11: 219.

17 Fassnacht M, Berruti A, Baudin E, Demeure MJ, Gilbert J, Haak H et al. Linsitinib (OSI-906) versus placebo for patients with locally advanced or metastatic adrenocortical carcinoma: a double-blind, randomised, phase 3 study. Lancet Oncol 2015; 16: 426-435.

18 Altieri B, Ronchi CL, Kroiss M, Fassnacht M. Next-generation therapies for adrenocortical carcinoma. Best Pract Res Clin Endocrinol Metab 2020; 34: 101434.

19 Herrmann LJ, Heinze B, Fassnacht M, Willenberg HS, Quinkler M, Reisch N et al. TP53 germline mutations in adult patients with adrenocortical carcinoma. J Clin Endocrinol Metab 2012; 97: E476-485.

20 Raymond VM, Else T, Everett JN, Long JM, Gruber SB, Hammer GD. Prevalence of germline TP53 mutations in a prospective series of unselected patients with adrenocortical carcinoma. $J$ Clin Endocrinol Metab 2013; 98: E119-125.

21 Raymond VM, Everett JN, Furtado LV, Gustafson SL, Jungbluth CR, Gruber SB et al. Adrenocortical carcinoma is a lynch syndrome-associated cancer. J Clin Oncol 2013; 31: 3012-3018.

22 Germano G, Lamba S, Rospo G, Barault L, Magri A, Maione F et al. Inactivation of DNA repair triggers neoantigen generation and impairs tumour growth. Nature 2017; 552: 116-120.

23 Fancello L, Gandini S, Pelicci PG, Mazzarella L. Tumour mutational burden quantification from targeted gene panels: major advancements and challenges. $J$ Immunother Cancer 2019; 7: 183.

24 Le Tourneau C, Hoimes C, Zarwan C, Wong DJ, Bauer S, Claus R et al. Avelumab in patients with previously treated metastatic adrenocortical carcinoma: phase $1 \mathrm{~b}$ results from the JAVELIN solid tumour trial. J Immunother Cancer 2018; 6: 111.

25 Habra MA, Stephen B, Campbell M, Hess K, Tapia C, Xu M et al. Phase II clinical trial of pembrolizumab efficacy and safety in advanced adrenocortical carcinoma. J Immunother Cancer 2019; 7: 253.

26 Carneiro BA, Konda B, Costa RB, Costa RLB, Sagar V, Gursel DB et al. Nivolumab in Metastatic Adrenocortical Carcinoma: Results of a Phase 2 Trial. J Clin Endocrinol Metab 2019; 104: 6193-6200.

27 Raj N, Zheng Y, Kelly V, Katz SS, Chou J, Do RKG et al. PD-1 Blockade in Advanced Adrenocortical Carcinoma. J Clin Oncol 2020; 38: 71-80.

28 Lang J, Capasso A, Jordan KR, French JD, Kar A, Bagby SM et al. Development of an Adrenocortical Cancer Humanized Mouse Model to Characterize Anti-PD1 Effects on Tumour Microenvironment. J Clin Endocrinol Metab 2020; 105. 
29 Volkov NM, Yanus GA, Ivantsov AO, Moiseenko FV, Matorina OG, Bizin IV et al. Efficacy of immune checkpoint blockade in MUTYH-associated hereditary colorectal cancer. Invest New Drugs 2020; 38: 894898.

30 Pilati C, Shinde J, Alexandrov LB, Assie G, Andre T, Helias-Rodzewicz Z et al. Mutational signature analysis identifies MUTYH deficiency in colorectal cancers and adrenocortical carcinomas. $J$ Pathol 2017; 242: 10-15.

31 Landwehr LS, Altieri B, Schreiner J, Sbiera I, Weigand I, Kroiss M et al. Interplay between glucocorticoids and tumour-infiltrating lymphocytes on the prognosis of adrenocortical carcinoma. $J$ Immunother Cancer 2020; 8.

32 Gazdar AF, Oie HK, Shackleton CH, Chen TR, Triche TJ, Myers CE et al. Establishment and characterization of a human adrenocortical carcinoma cell line that expresses multiple pathways of steroid biosynthesis. Cancer Res 1990; 50: 5488-5496.

33 Pinto EM, Kiseljak-Vassiliades K, Hantel C. Contemporary preclinical human models of adrenocortical carcinoma. Curr Opin Endocr Metab Res 2019; 8: 139-144.

34 Hantel C, Shapiro I, Poli G, Chiapponi C, Bidlingmaier M, Reincke M et al. Targeting heterogeneity of adrenocortical carcinoma: Evaluation and extension of preclinical tumour models to improve clinical translation. Oncotarget 2016; 7: 79292-79304.

35 Kiseljak-Vassiliades K, Zhang Y, Bagby SM, Kar A, Pozdeyev N, Xu M et al. Development of new preclinical models to advance adrenocortical carcinoma research. Endocr Relat Cancer 2018; 25: 437451.

36 Weigand I, Schreiner J, Rohrig F, Sun N, Landwehr LS, Urlaub H et al. Active steroid hormone synthesis renders adrenocortical cells highly susceptible to type II ferroptosis induction. Cell Death Dis 2020; 11: 192.

37 Siebert C, Ciato D, Murakami M, Frei-Stuber L, Perez-Rivas LG, Monteserin-Garcia JL et al. Heat Shock Protein 90 as a Prognostic Marker and Therapeutic Target for Adrenocortical Carcinoma. Front Endocrinol (Lausanne) 2019; 10: 487.

38 Kiseljak-Vassiliades K, Zhang Y, Kar A, Razzaghi R, Xu M, Gowan K et al. Elucidating the Role of the Maternal Embryonic Leucine Zipper Kinase in Adrenocortical Carcinoma. Endocrinology 2018; 159: 25322544.

39 Liu X, Ory V, Chapman S, Yuan H, Albanese C, Kallakury B et al. ROCK inhibitor and feeder cells induce the conditional reprogramming of epithelial cells. Am J Pathol 2012; 180: 599-607.

40 Motulsky HJ. Confidence intervals of parameters, GraphPad Curve Fitting Guide2016. 
41 Kurlbaum M, Sbiera S, Kendl S, Fassnacht M, Kroiss M. Steroidogenesis in the NCl-H295 Cell Line Model is Strongly Affected By Culture Conditions and Substrain. Exp Clin Endocrinol Diabetes 2020.

42 Martin M. Cutadapt removes adapter sequences from high-throughput sequencing reads. EMBnet journal, 2011; 17: 10-12.

$43 \mathrm{Li} \mathrm{H}$, Durbin R. Fast and accurate short read alignment with Burrows-Wheeler transform. Bioinformatics 2009; 25: 1754-1760.

$44 \mathrm{Li} \mathrm{H}$, Handsaker B, Wysoker A, Fennell T, Ruan J, Homer N et al. The Sequence Alignment/Map format and SAMtools. Bioinformatics 2009; 25: 2078-2079.

45 McKenna A, Hanna M, Banks E, Sivachenko A, Cibulskis K, Kernytsky A et al. The Genome Analysis Toolkit: a MapReduce framework for analyzing next-generation DNA sequencing data. Genome Res 2010; 20: 1297-1303.

46 Wang K, Li M, Hakonarson H. ANNOVAR: functional annotation of genetic variants from highthroughput sequencing data. Nucleic Acids Res 2010; 38: e164.

47 Goncearenco A, Rager SL, Li M, Sang QX, Rogozin IB, Panchenko AR. Exploring background mutational processes to decipher cancer genetic heterogeneity. Nucleic Acids Res 2017; 45: W514-W522.

48 Sbiera S, Leich E, Liebisch G, Sbiera I, Schirbel A, Wiemer L et al. Mitotane Inhibits Sterol-O-Acyl Transferase 1 Triggering Lipid-Mediated Endoplasmic Reticulum Stress and Apoptosis in Adrenocortical Carcinoma Cells. Endocrinology 2015; 156: 3895-3908.

49 Viel A, Bruselles A, Meccia E, Fornasarig M, Quaia M, Canzonieri V et al. A Specific Mutational Signature Associated with DNA 8-Oxoguanine Persistence in MUTYH-defective Colorectal Cancer. EBioMedicine 2017; 20: 39-49.

50 Sbiera S, Schmull S, Assie G, Voelker HU, Kraus L, Beyer M et al. High diagnostic and prognostic value of steroidogenic factor-1 expression in adrenal tumours. J Clin Endocrinol Metab 2010; 95: E161-171.

51 AlDubayan SH, Giannakis M, Moore ND, Han GC, Reardon B, Hamada T et al. Inherited DNA-Repair Defects in Colorectal Cancer. Am J Hum Genet 2018; 102: 401-414.

52 Le DT, Durham JN, Smith KN, Wang H, Bartlett BR, Aulakh LK et al. Mismatch repair deficiency predicts response of solid tumours to PD-1 blockade. Science 2017; 357: 409-413.

53 Mota JM, Sousa LG, Braghiroli MI, Siqueira LT, Neto JEB, Chapchap P et al. Pembrolizumab for metastatic adrenocortical carcinoma with high mutational burden Two case reports. Medicine 2018; 97.

54 Al-Tassan N, Chmiel NH, Maynard J, Fleming N, Livingston AL, Williams GT et al. Inherited variants of MYH associated with somatic G:C-->T:A mutations in colorectal tumours. Nat Genet 2002; 30: 227-232. 
55 Nielsen M, Morreau H, Vasen HF, Hes FJ. MUTYH-associated polyposis (MAP). Crit Rev Oncol Hematol 2011; 79: 1-16.

56 Hellmann MD, Callahan MK, Awad MM, Calvo E, Ascierto PA, Atmaca A et al. Tumour Mutational Burden and Efficacy of Nivolumab Monotherapy and in Combination with Ipilimumab in Small-Cell Lung Cancer. Cancer Cell 2018; 33: 853-861 e854.

57 Reichel MB, Ohgaki H, Petersen I, Kleihues P. p53 mutations in primary human lung tumours and their metastases. Mol Carcinog 1994; 9: 105-109.

58 Shah SP, Roth A, Goya R, Oloumi A, Ha G, Zhao Y et al. The clonal and mutational evolution spectrum of primary triple-negative breast cancers. Nature 2012; 486: 395-399.

\section{Tables}

Due to technical limitations, table 1 is only available as a download in the Supplemental Files section.

\section{Figures}


A

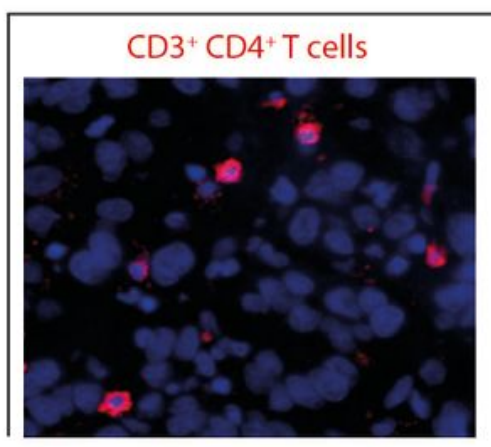

primary tumour

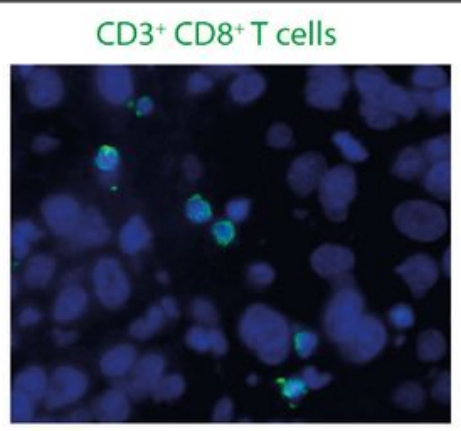

JIL-2266

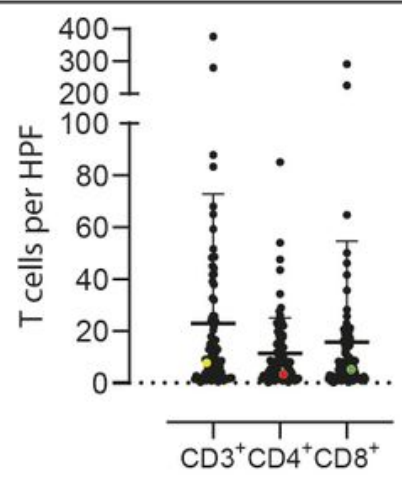

H295R

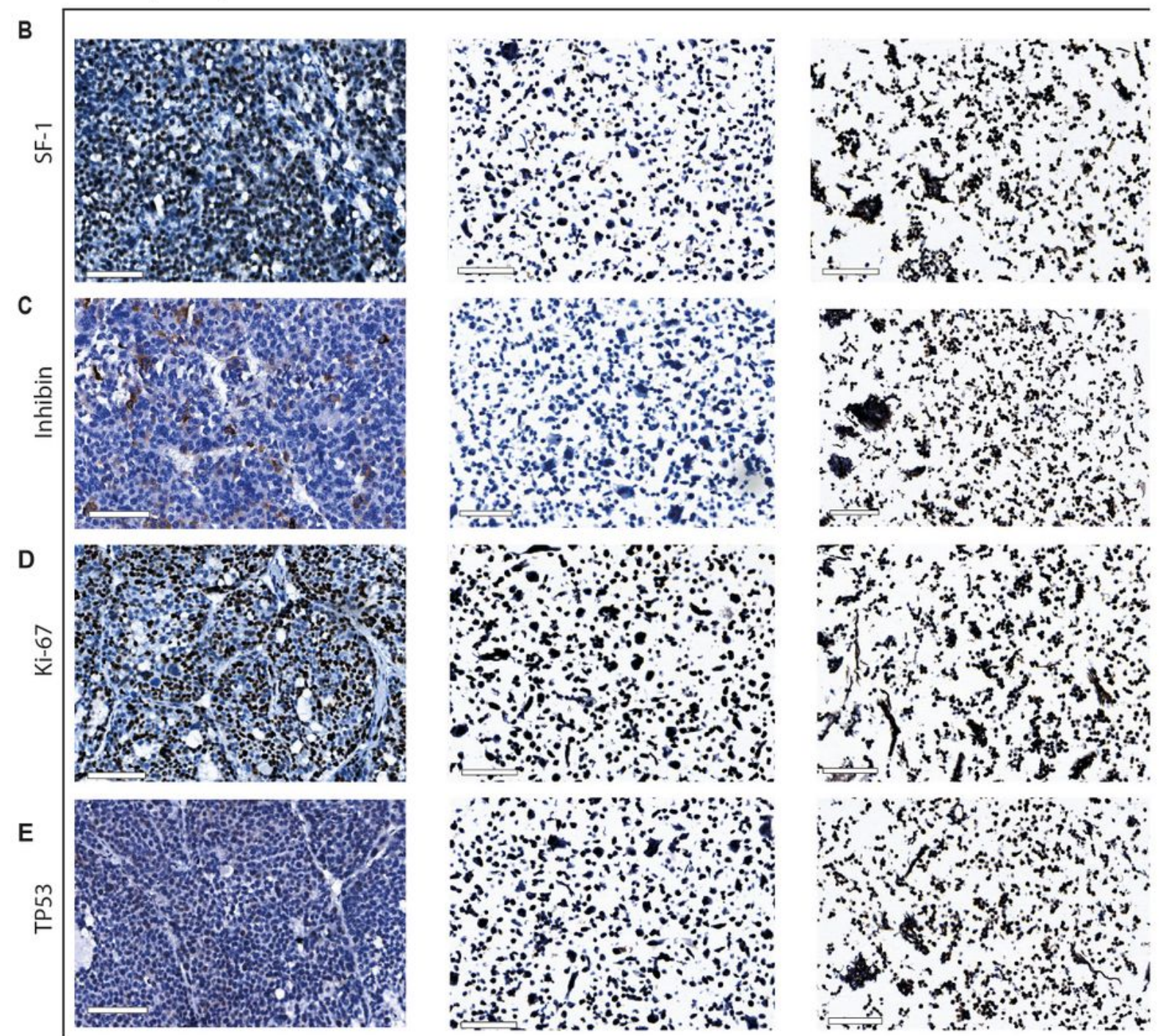

Figure 1

Immunofluorescence staining (40 x magnification) and quantification of CD3+-, CD4+- and CD8+ tumourinfiltrating lymphocytes of patient-derived primary ACC (coloured dots) compared to other primary ACCs (A). Immunohistochemistry of FFPE tissue of the primary ACC and cell pellets from JIL-2266 and H295R cells and morphological investigation of JIL-2266 cells. (B) SF-1 staining, (C) inhibin a staining, (D) Ki-67 and (E) TP53 staining, scale bars: $100 \mu \mathrm{M}$. 
A

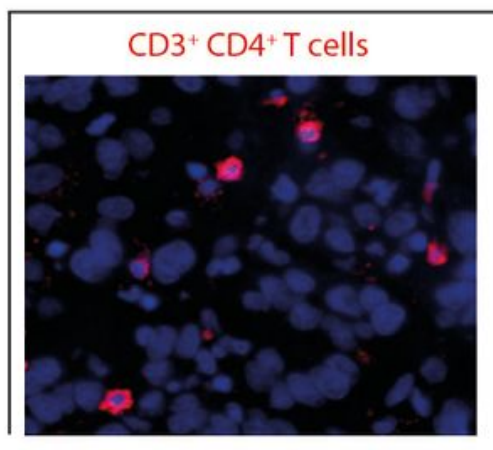

primary tumour

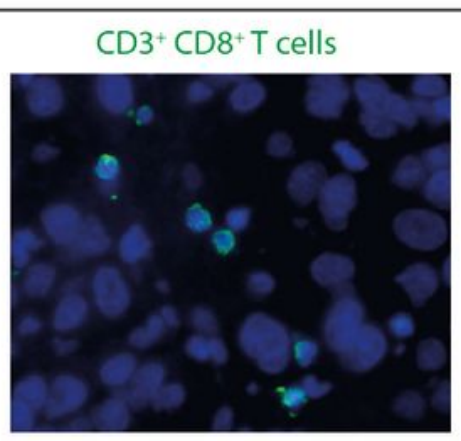

JIL-2266

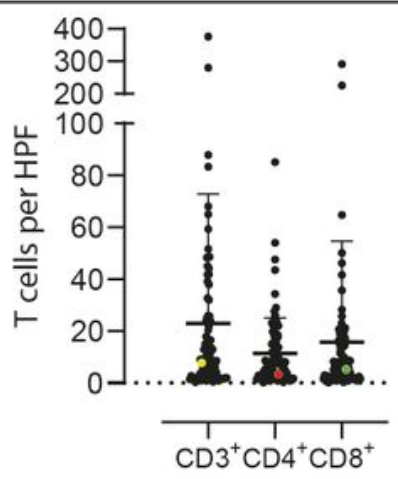

H295R

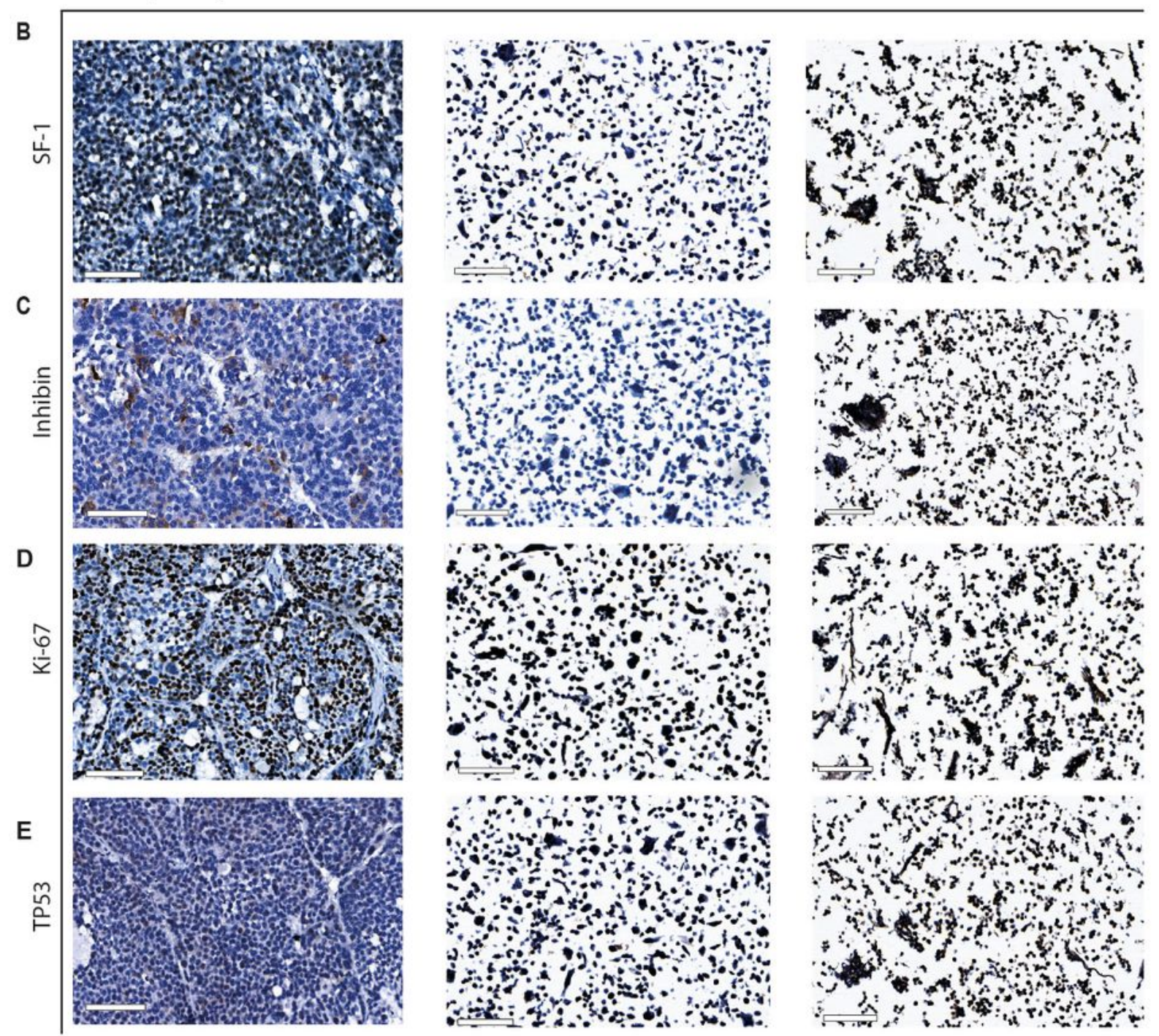

Figure 1

Immunofluorescence staining (40 x magnification) and quantification of CD3+-, CD4+- and CD8+ tumourinfiltrating lymphocytes of patient-derived primary ACC (coloured dots) compared to other primary ACCs (A). Immunohistochemistry of FFPE tissue of the primary ACC and cell pellets from JIL-2266 and H295R cells and morphological investigation of JIL-2266 cells. (B) SF-1 staining, (C) inhibin a staining, (D) Ki-67 and (E) TP53 staining, scale bars: $100 \mu \mathrm{M}$. 

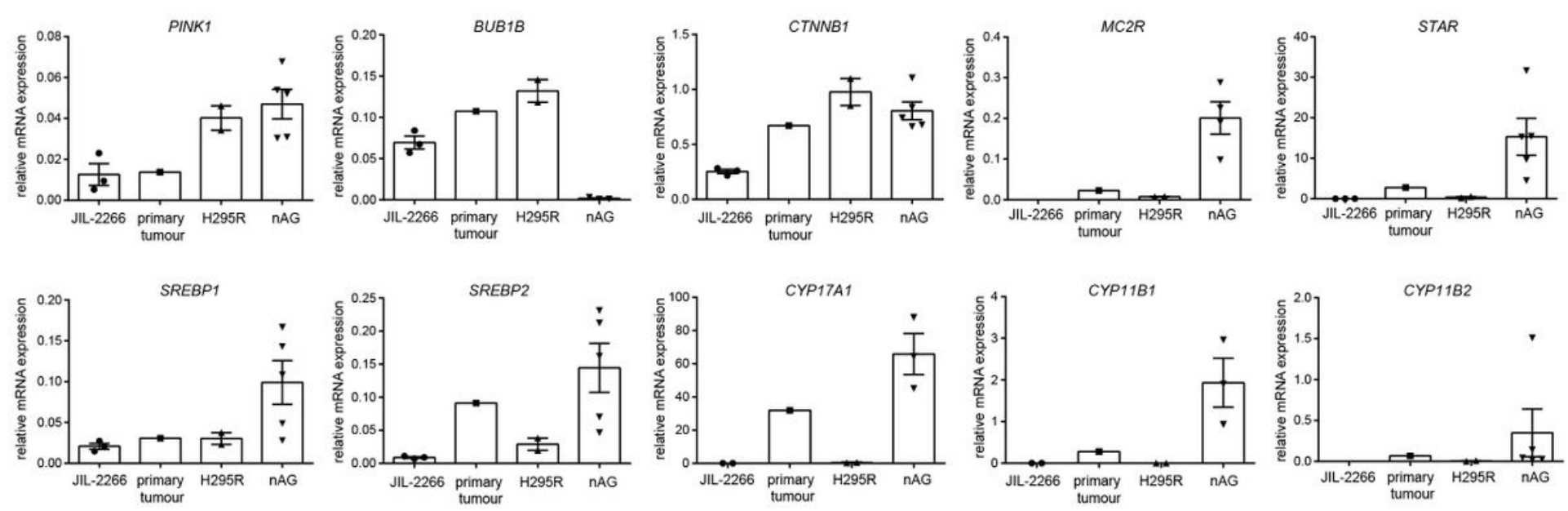

Figure 2

mRNA expression of different ACC markers (BUB1B, PINK1 and CTNNB1) and steroidogenic markers in the JIL-2266 cell line, its corresponding primary tumour, H295R cells and five normal adrenal glands (nAG), analysed by RT-qPCR.
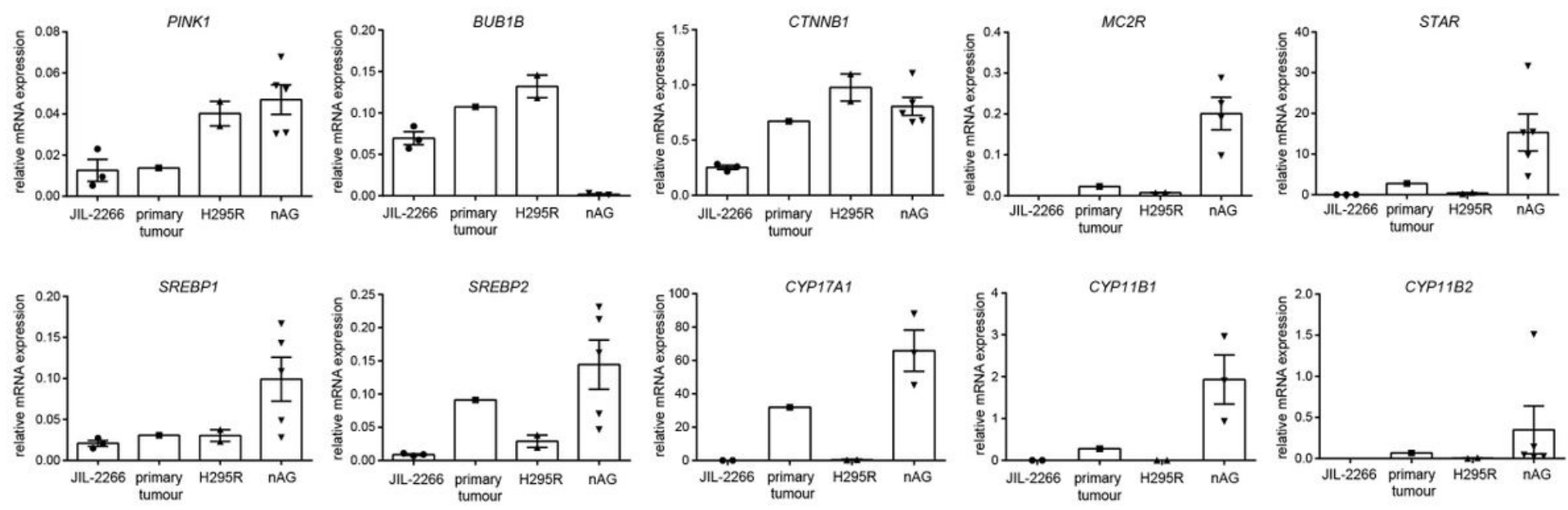

Figure 2

mRNA expression of different ACC markers (BUB1B, PINK1 and CTNNB1) and steroidogenic markers in the JIL-2266 cell line, its corresponding primary tumour, H295R cells and five normal adrenal glands (nAG), analysed by RT-qPCR. 

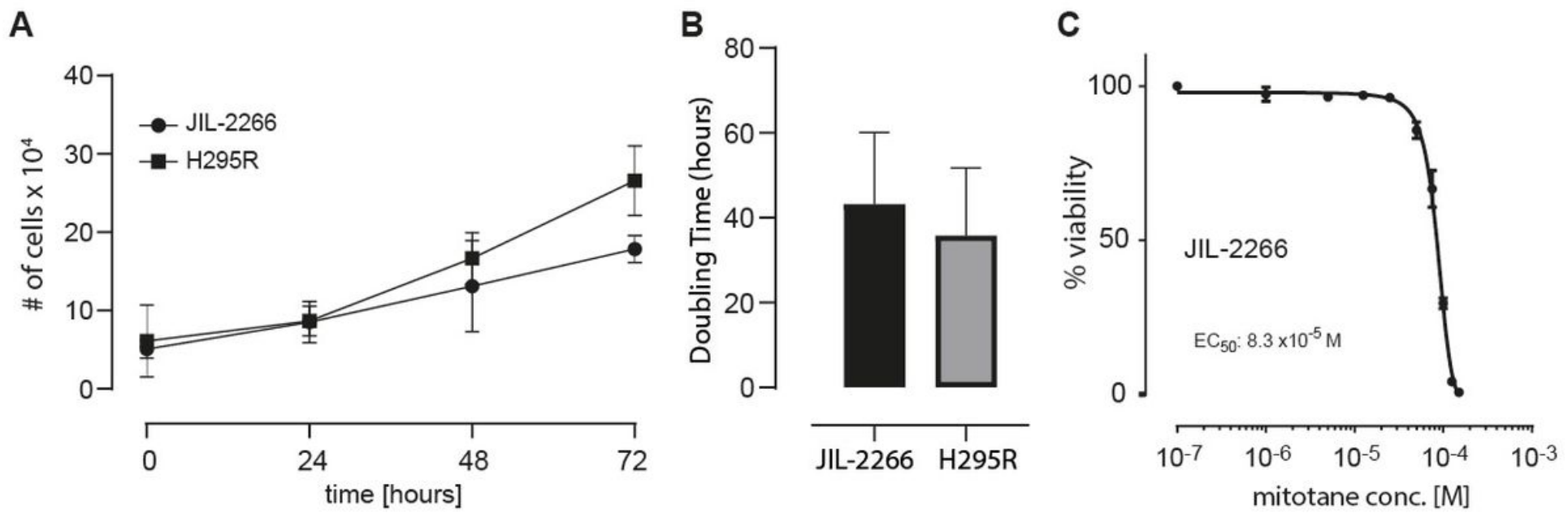

Figure 3

Proliferation of JIL-2266 cells and their response to mitotane treatment. (A) JIL-2266 cells proliferate in culture, yet at a lower rate than H295R cells. Doubling time of JIL-2266 cells is $41 \mathrm{~h}$ while H295R cells have a doubling time of $36 \mathrm{~h}$. (C) JIL-2266 were unresponsive to mitotane treatment with an EC50 value of $8.3 \times 10-5$ after $24 \mathrm{~h}$.
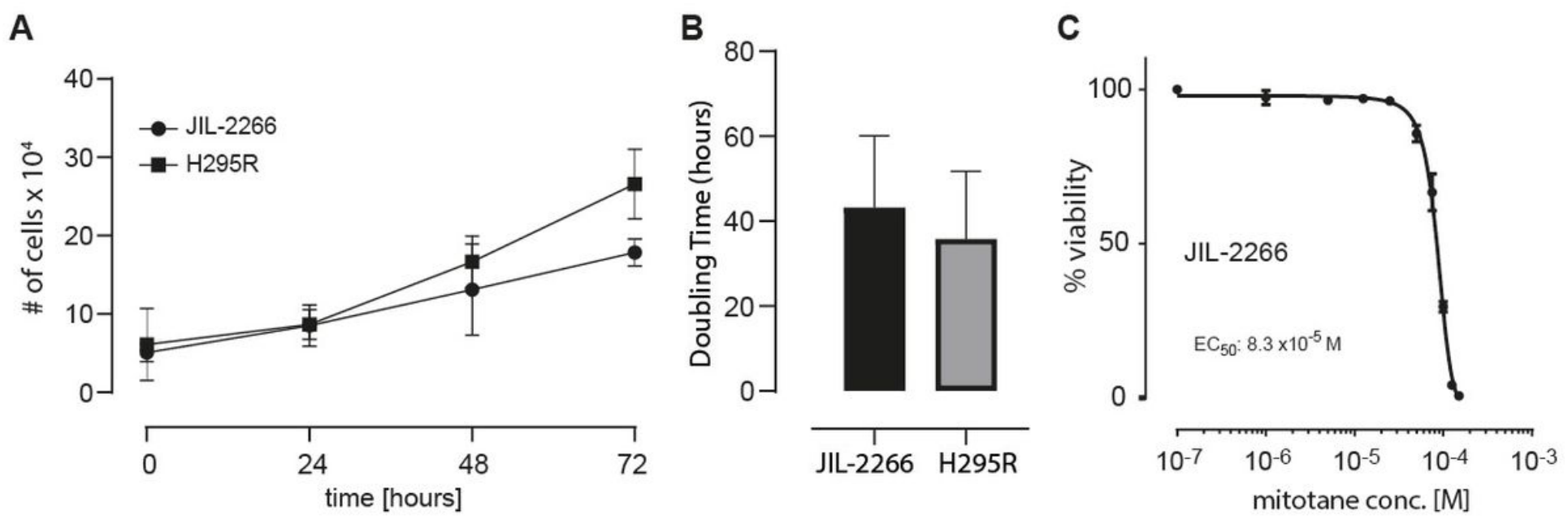

\section{Figure 3}

Proliferation of JIL-2266 cells and their response to mitotane treatment. (A) JIL-2266 cells proliferate in culture, yet at a lower rate than H295R cells. Doubling time of JIL-2266 cells is $41 \mathrm{~h}$ while H295R cells have a doubling time of $36 \mathrm{~h}$. (C) JIL-2266 were unresponsive to mitotane treatment with an EC50 value of $8.3 \times 10-5$ after $24 \mathrm{~h}$. 


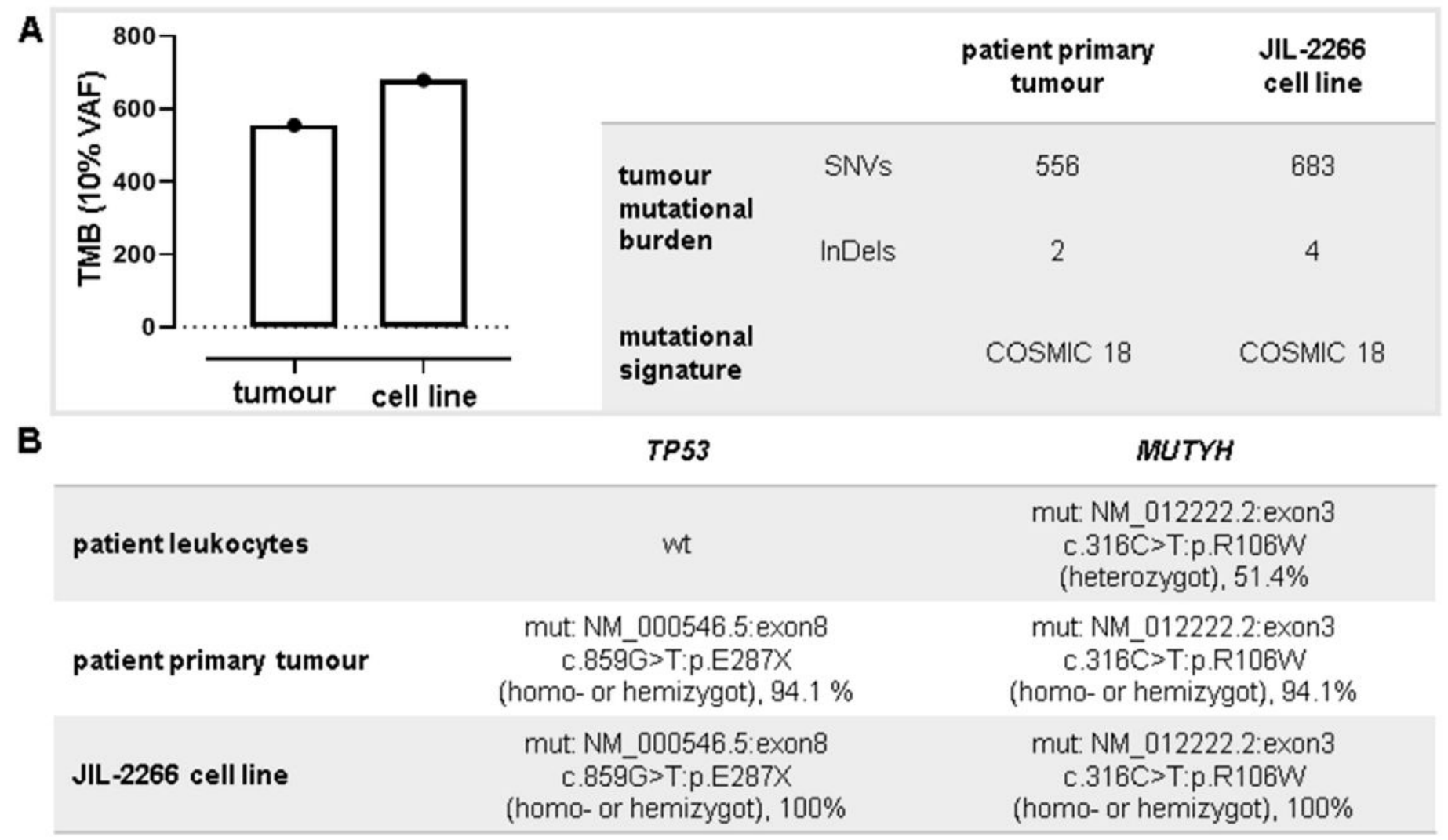

\section{Figure 4}

Whole exome sequencing of human primary tumour, JIL-2266 cell line and leukocyte reference. (A) Tumour mutational burden (TMB) with $10 \%$ variant allele frequency cut-off increases from primary tumour to JIL-2266 cell line, while mutational signature remained stable. (B) Exome sequencing analysis of human tumour, JIL-2266 cell line and blood demonstrated evidence of TP53 and MUTYH mutation in primary tumour and corresponding JIL-2266 cell line. 


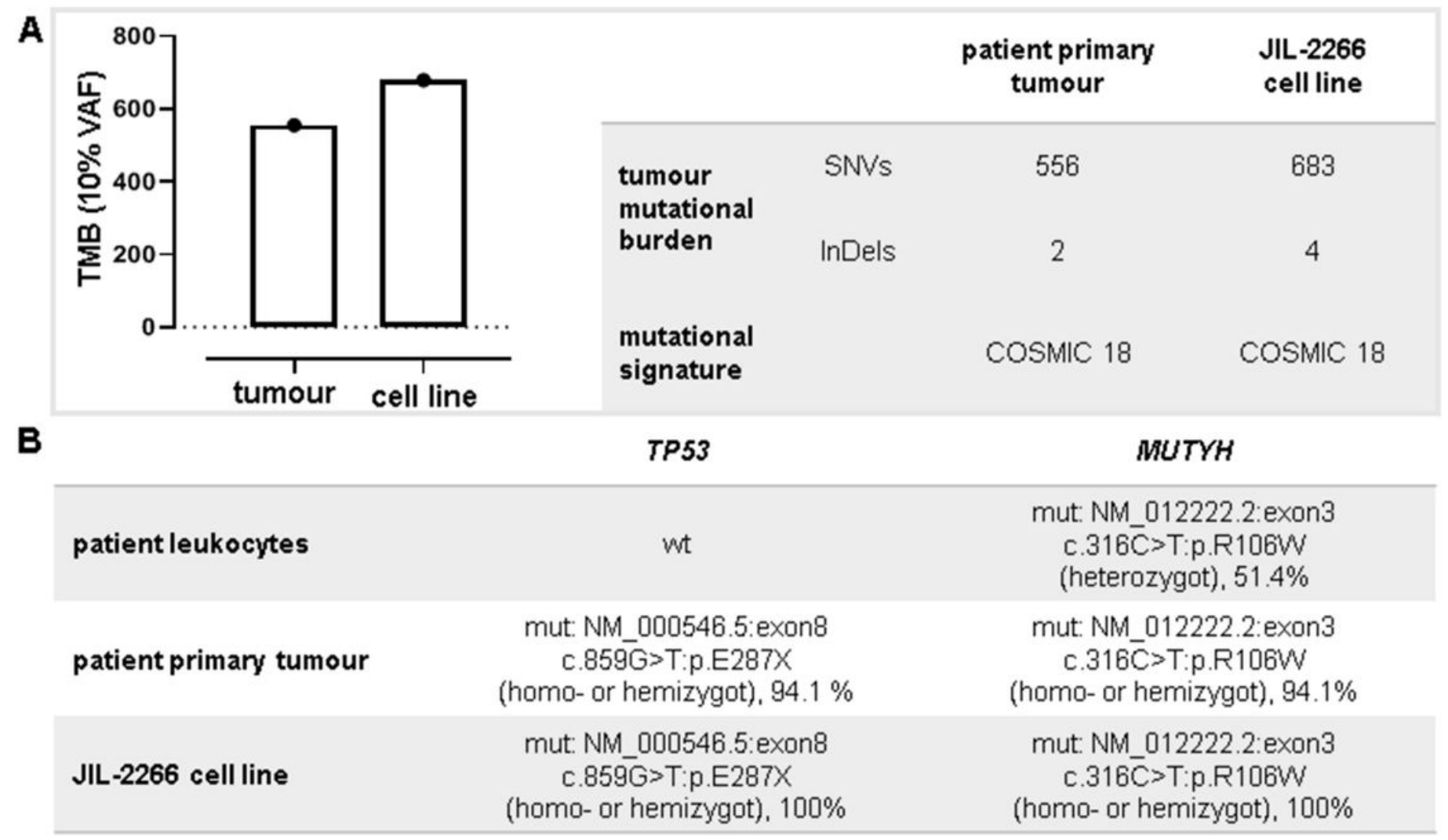

\section{Figure 4}

Whole exome sequencing of human primary tumour, JIL-2266 cell line and leukocyte reference. (A) Tumour mutational burden (TMB) with $10 \%$ variant allele frequency cut-off increases from primary tumour to JIL-2266 cell line, while mutational signature remained stable. (B) Exome sequencing analysis of human tumour, JIL-2266 cell line and blood demonstrated evidence of TP53 and MUTYH mutation in primary tumour and corresponding JIL-2266 cell line. 


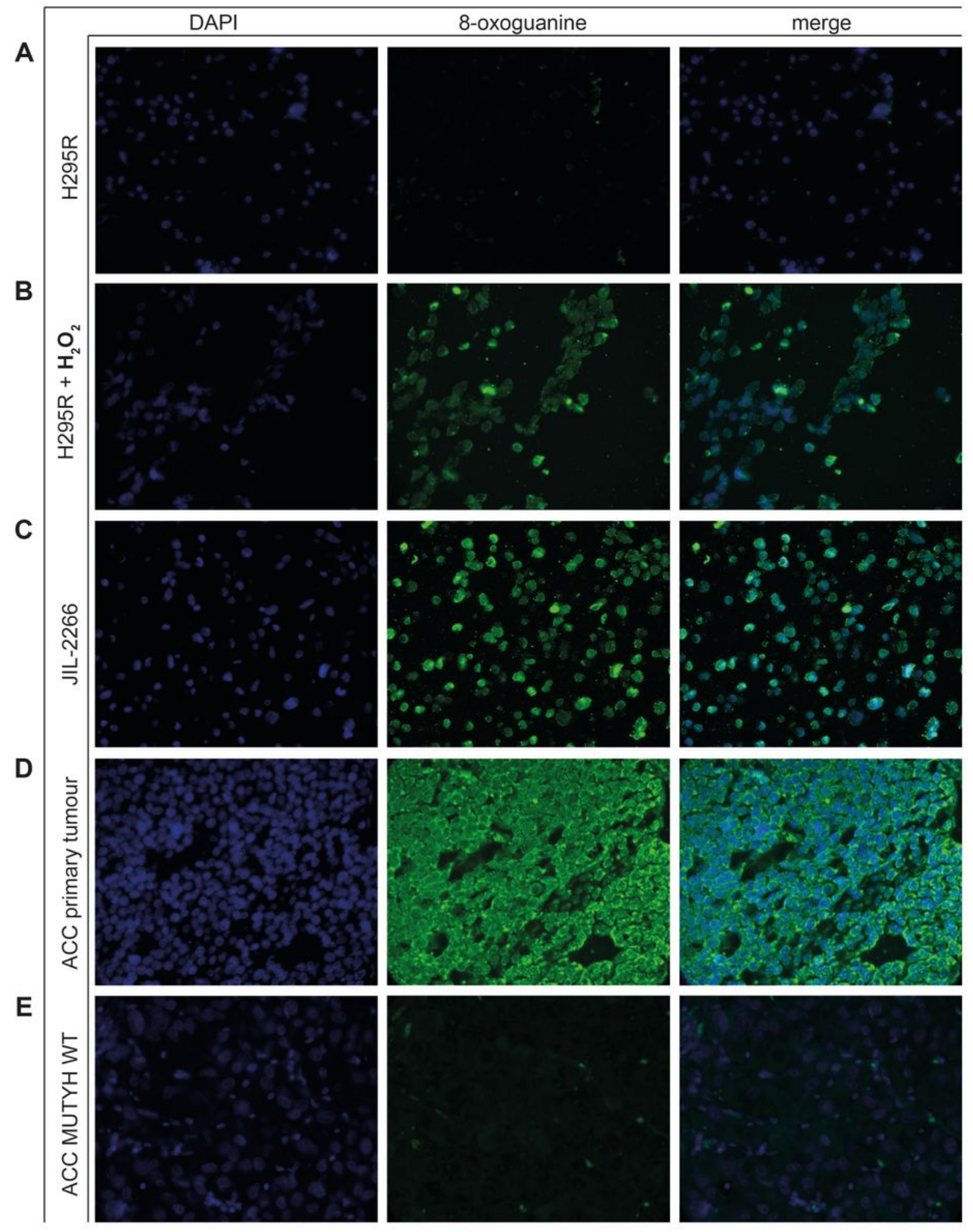

Figure 5

Immunofluorescence staining of 8-oxoguanine in FFPE cell pellets and ACC tissues. (A) Untreated H295R cells stained negative for 8-oxoguanine, while (B) H2O2 treatment strongly increased 8-oxoguanine staining positivity. (C) Untreated JIL-2266 cells showed a strong 8-oxoguanine staining positivity as the corresponding primary tumour (D). (E) In a MUTYH WT ACC, 8-oxoguanine staining was negative. DAPI was used to stain nuclei. 


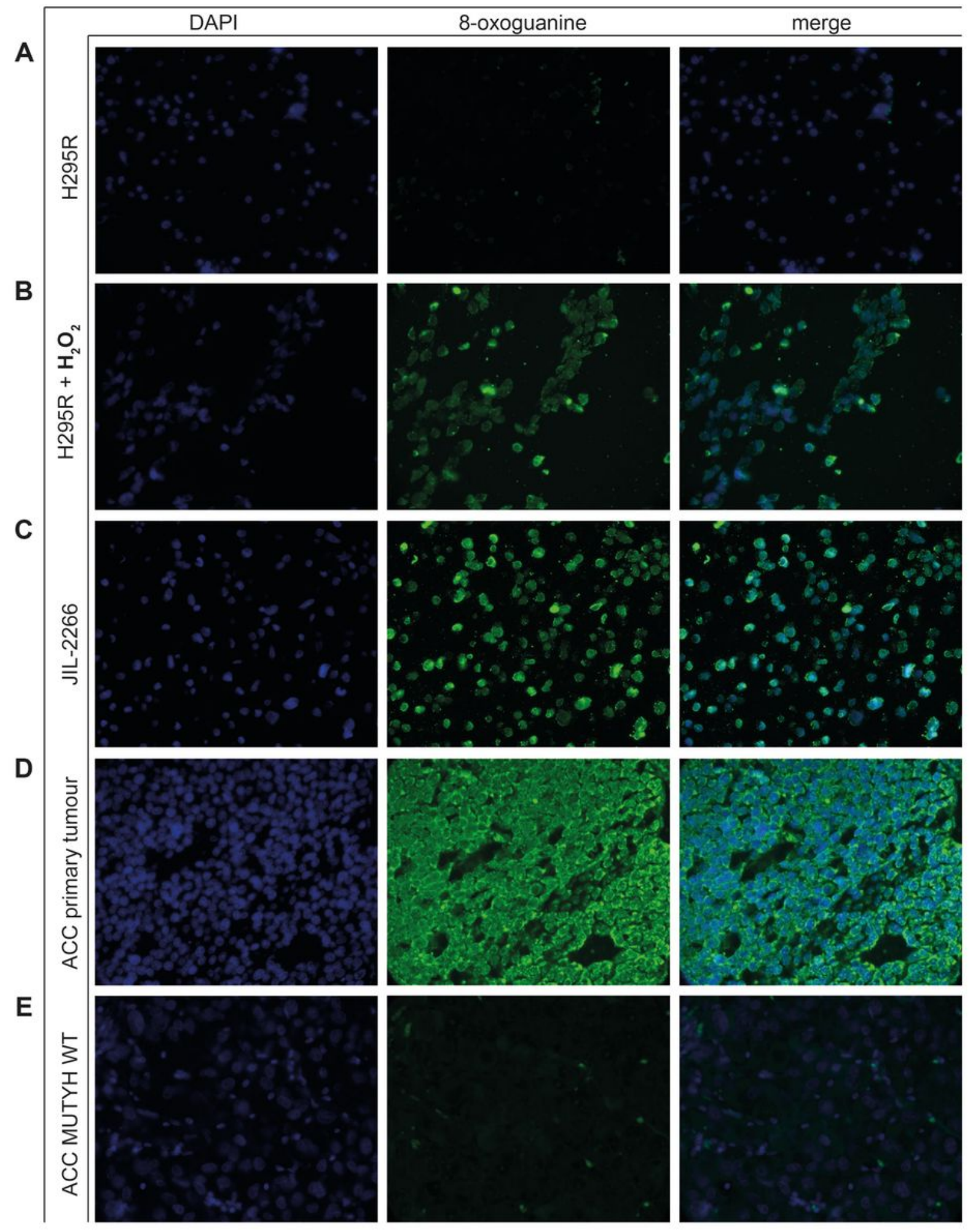

Figure 5

Immunofluorescence staining of 8-oxoguanine in FFPE cell pellets and ACC tissues. (A) Untreated H295R cells stained negative for 8-oxoguanine, while (B) H2O2 treatment strongly increased 8-oxoguanine staining positivity. (C) Untreated JIL-2266 cells showed a strong 8-oxoguanine staining positivity as the corresponding primary tumour (D). (E) In a MUTYH WT ACC, 8-oxoguanine staining was negative. DAPI was used to stain nuclei. 


\section{Supplementary Files}

This is a list of supplementary files associated with this preprint. Click to download.

- SupplemenatryTable1.xIsx

- SupplemenatryTable1.xlsx

- SupplementaryFigure1.jpg

- SupplementaryFigure1.jpg

- SupplementaryFigure2.pdf

- SupplementaryFigure2.pdf

- SupplementaryTable2.xlsx

- SupplementaryTable2.xlsx

- Supplementaryinformation.docx

- Supplementaryinformation.docx

- Table1.pdf

- Table1.pdf 